\title{
Acquired Senescent T-Cell Phenotype Correlates with Clinical Severity in GATA Binding Protein 2-Deficient Patients
}

OPEN ACCESS

Edited by:

Guzide Aksu,

Ege University, Turkey

Reviewed by:

Elham Hossny,

Ain Shams University, Egypt

George Makedonas,

Baylor College of Medicine,

United States

${ }^{*}$ Correspondence:

Raquel Ruiz-García

rruizg@salud.madrid.org

†Luis Ignacio González-Granado and Luis Miguel Allende contributed equally to this work.

Specialty section:

This article was submitted to Primary Immunodeficiencies,

a section of the journal

Frontiers in Immunology

Received: 06 April 2017

Accepted: 26 June 2017

Published: 12 July 2017

Citation:

Ruiz-García R, Rodríguez-Vigil $C$

Marco FM, Gallego-Bustos F,

Castro-Panete MJ, Diez-Alonso L, Muñoz-Ruiz C, Ruiz-Contreras J,

Paz-Artal E, González-Granado LI and Allende LM (2017) Acquired

Senescent T-Cell Phenotype

Correlates with Clinical Severity

in GATA Binding Protein

2-Deficient Patients.

Front. Immunol. 8:802.

doi: 10.3389/fimmu.2017.00802

\author{
Raquel Ruiz-García ${ }^{1,2 *}$, Carmen Rodríguez-Vigil' ${ }^{3}$,Francisco Manuel Marco ${ }^{4}$, \\ Fernando Gallego-Bustos ', María José Castro-Panete ${ }^{1,2}$, Laura Diez-Alonso', \\ Carlos Muñoz-Ruiz ${ }^{4}$, Jesús Ruiz-Contreras ${ }^{2,5}$, Estela Paz-Artal 1,2,6,7, \\ Luis Ignacio González-Granado ${ }^{2,5 t}$ and Luis Miguel Allende ${ }^{1,2+}$
}

${ }^{1}$ Servicio de Inmunología, Hospital Universitario 12 de Octubre, Madrid, Spain, 2nstituto de Investigación 1+12, Hospital Universitario 12 de Octubre, Madrid, Spain, ${ }^{3}$ Servicio de Hemato-Oncología Pediátrica, Hospital Universitario Miguel Servet, Zaragoza, Spain, ${ }^{4}$ Sección de Inmunología, Hospital General Universitario de Alicante, Alicante, Spain, ${ }^{5}$ Unidad de Inmunodeficiencias, Servicio de Pediatría, Hospital Universitario 12 de Octubre, Madrid, Spain, ${ }^{6}$ Facultad de Medicina, Universidad Complutense de Madrid, Madrid, Spain, ' Sección de Inmunología, Universidad de San Pablo CEU, Madrid, Spain

GATA binding protein 2 (GATA2) deficiency is a rare disorder of hematopoiesis, lymphatics, and immunity caused by spontaneous or autosomal dominant mutations in the GATA2 gene. Clinical manifestations range from neutropenia, lymphedema, deafness, to severe viral and mycobacterial infections, bone marrow failure, and acute myeloid leukemia. Patients also present with monocytopenia, dendritic cell, B- and natural killer (NK)-cell deficiency. We studied the T-cell and NK-cell compartments of four GATA2-deficient patients to assess if changes in these lymphocyte populations could be correlated with clinical phenotype. Patients with more severe clinical complications demonstrated a senescent T-cell phenotype whereas patients with lower clinical score had undetectable changes relative to controls. In contrast, patients' NK-cells demonstrated an immature/ activated phenotype that did not correlate with clinical score, suggesting an intrinsic NK-cell defect. These studies will help us to determine the contribution of T- and NK-cell dysregulation to the clinical phenotype of GATA2 patients, and may help to establish the most accurate therapeutic options for these patients. Asymptomatic patients may be taken into consideration for hematopoietic stem cell transplantation when dysregulation of T-cell and NK-cell compartment is present.

Keywords: primary immunodeficiency, GATA binding protein 2, T-cell, natural killer-cell, myelodysplastic syndrome

\section{INTRODUCTION}

Spontaneous or autosomal dominant heterozygous mutations in GATA2 cause haploinsufficiency of the transcription factor GATA binding protein 2 (GATA2) (1). GATA2 is a zinc finger transcription factor essential for embryonic and definitive hematopoiesis as well as lymphatic angiogenesis (2). Germline mutations in GATA2 predispose patients to familial myelodysplastic syndrome (MDS), acute

Abbreviations: MDS, myelodysplastic syndrome; AML, acute myeloid leukemia; PBMCs, peripheral blood mononuclear cells; GATA2, GATA binding protein 2; VIN, vulvar intraepithelial neoplasia; CFSE, 5(6)-carboxyfluorescein diacetate N-succinimidyl ester; PI, propidium iodide; RAG1,2, recombination activating gene 1,2; CMV, cytomegalovirus; NK, natural killer. 
myeloid leukemia (AML) (3), "MonoMAC" syndrome of monocytopenia with predisposition to non-tuberculous mycobacterial infection (4, 5), Emberger syndrome (1), deafness, lymphedema, and the syndrome of dendritic cells (DCs), monocytes, and B and natural killer (NK) lymphoid deficiency ("DCML deficiency") (6).

The most common immunologic feature in GATA2-deficient patients is a B-cell lymphopenia, but with all maturation subsets present (7), they also have reduced numbers of monocytes and there are no circulating DCs. Furthermore, NK cells are diminished or partially absent with specific loss of the CD56 $6^{\text {bright }}$ subset $(8,9)$ and $\mathrm{T}$ cells are elevated in percentage but sometimes with reduced absolute counts due to overall lymphopenia (7). $\mathrm{CD}^{+}$lymphocytopenia (10) with reduced numbers of naïve $\mathrm{T}$ cells and an accumulation of $\mathrm{CD}^{+}$TEMRA have also been observed (9).

GATA binding protein 2 haploinsufficiency is caused by many different types of mutations, ranging from non-sense (stop codons and deletions), missense (amino acid substitutions), regulatory (intronic changes leading to monoallelic expression) to large deletions $(11,12)$. Interestingly, there is not an absolute correlation between genotype and phenotype in GATA2 deficiency, and patients with the same mutations may exhibit different clinical features ranging from isolated neutropenia or lymphedema to MDS, AML, or severe viral infections (10).

We report four GATA2-deficient patients with different clinical phenotypes. In order to better understand the genetic, immunologic, and clinical spectrum of GATA2 disease, we have performed phenotyping and functional analysis of $\mathrm{T}$ and NK cells in patients with both novel and previously described mutations. We observed dysregulation in both T- and NK-cell compartments that, in the case of $\mathrm{T}$ cells, correlated directly with a higher clinical score. This extends our previous understanding of GATA2 deficiency by defining T-cell defects in patients with severe clinical disease.

\section{MATERIALS AND METHODS}

\section{Blood Samples}

The study was approved by the clinical ethics committee of Hospital Universitario 12 de Octubre (Spain). Blood samples were obtained from the patients, their relatives, and healthy controls after they had given written informed consent in agreement with the principles of the Declaration of Helsinki. Patients or their parents/guardians gave written consent to publish the case reports.

\section{DNA Sequencing}

Genomic DNA was extracted from peripheral blood samples using QIAmp DNA Mini Kit (Qiagen, Hilden, Germany). GATA2 was directly sequenced in patients $\mathrm{P} 1, \mathrm{P} 2$, and $\mathrm{P} 4$ using specific primers and conditions described in Table S1 in Supplementary Material. The GATA2 mutation in P3 was identified by targeted sequencing with an in-house designed panel of 192 genes involved in PID (Ampliseq, Life Technologies) and confirmed by Sanger sequencing.

\section{Flow Cytometry}

Immunophenotyping was performed on peripheral blood for the identification of T, B, and NK cells. Intracytoplasmatic staining of cytotoxic granules in CD8 and NK cells was performed using FACSLysing and PermII buffers (BD Bioscience, Madrid, Spain). Analysis of NK-cell surface markers in GATA2-deficient patients was done in $\geq 200 \mathrm{NK}$ cells per patient. Conjugated anti-human monoclonal antibodies are listed in Table S2 in Supplementary Material. Flow cytometry data were collected using a Beckman Coulter Navios cytometer and analyzed with Kaluza 1.5a software (Beckman Coulter, Madrid, Spain).

\section{NK-Cell Cytotoxicity Assays}

NK-cell cytotoxic function was tested as described in Ref. (13). Briefly, peripheral blood mononuclear cells were co-cultured with 5(6)-carboxyfluorescein diacetate $N$-succinimidyl ester (CFSE) labeled K562 erythroleukemia cells at different ratios for $4 \mathrm{~h}$ in the presence or absence of exogenous IL-2. Dead cells were measured as CFSE+PI+K562 cells. The percentage of specific lysis was calculated in all cases according to the formula: $\%$ specific lysis $=[($ experimental - spontaneous $) /($ maximum release - spontaneous release) $] \times 100$.

\section{Statistics}

Statistical analysis was performed using Prism 6.0 (GraphPad). Two-tailed Student's $t$-test with Welch's correction when variances were significantly different was applied. The results were considered significant when $P$-values were $<0.05\left(^{*}\right),<0.01\left(^{* *}\right),<0.001$ $(* * *)$.

\section{RESULTS}

\section{Patients: Case Reports, Genetics, and Immunological Features}

Patient 1 is a 12 -year old female that was diagnosed in a routine work-up for neutropenia. Monocytopenia, B, and NK lymphopenia (Table 1) were highly suggestive of GATA2 deficiency. Sanger sequencing revealed a heterozygous non-sense mutation in GATA2 (c.1009C>T; p.R337X) (1). Initial bone marrow aspirate at the age of 12 years (age of presentation) was performed and was normocellular. However, a subsequent bone marrow evaluation (age 14) showed hypoplasia and myelodysplasia (normal immunophenotype and cytogenetic analysis). Blood or platelet transfusions have not been required and she is awaiting hematopoietic stem cell transplantation (HSCT) from an unrelated donor. Despite B- and NK-cell lymphopenia, her T-cell compartment showed normal percentages of CD4 and CD8 T cells and normal absolute lymphocyte counts.

Patient 2 is a 27 -year old male whose clinical features were described in Ref. (14). He had suffered severe complications related to GATA2 deficiency: an extensive vesicular rash, later confirmed positive for HSV-2 by viral culture, that began on his left toe and spread to affect the entire surface of his left lower extremity, accompanied by a stable moderate lymphedema in his left leg. In addition to anemia and neutropenia, immunophenotyping revealed B- and NK-cell lymphopenia with the absence 
TABLE 1 | Immunologic features of the patients.

\begin{tabular}{|c|c|c|c|c|c|c|}
\hline Variables & $\begin{array}{c}\text { Normal range } \\
\text { children }\end{array}$ & $\begin{array}{c}\text { Normal range } \\
\text { adults }\end{array}$ & P1 (12 years) & P2 (26 years) & P3 (11 years) & P4 (32 years) \\
\hline Neutrophils $(n \% \mu \mathrm{L})$ & $1,800-7,600$ & $1,800-7,400$ & 1,800 & 6,600 & 800 & 6,310 \\
\hline Monocytes ( $\mathrm{n} / \mu \mathrm{L})$ & $200-900$ & $300-900$ & 16 & 7 & 250 & 217 \\
\hline Lymphocyte (n\% $/ \mu \mathrm{L})$ & $1,500-4,000$ & $1,200-3,000$ & 3,169 & 679 & 913 & 2,188 \\
\hline \multicolumn{7}{|l|}{ T cells } \\
\hline $\mathrm{CD}^{+}\left(\mathrm{n}^{\circ} / \mu \mathrm{L}\right)$ & $800-2,600$ & $850-2,250$ & 3,106 & 638 & 880 & 2,168 \\
\hline $\mathrm{CD}^{+}\left(\mathrm{n}^{\circ} / \mu \mathrm{L}\right)$ & $600-1,500$ & $500-1,450$ & 1,648 & 285 & 240 & 905 \\
\hline $\mathrm{CD}^{+}(\mathrm{n} \% / \mathrm{L})$ & $250-1,000$ & $160-950$ & 1,458 & 319 & 492 & 1,206 \\
\hline DN T cells CD3+TCR $\alpha \beta^{+}{ }^{+}{ }^{+} D 4^{-}{ }^{-C D} 8^{-}(\%)$ & $0-4$ & $0-4$ & 0.3 & 0.6 & 2.7 & 0.4 \\
\hline $\mathrm{CD} 4{ }^{+} \mathrm{CD} 45 \mathrm{RA}^{+} \mathrm{CD} 31^{+}(\%)$ & $44-60$ & $20-44$ & 63 & 31 & 16 & NA \\
\hline \multicolumn{7}{|l|}{ T-cell proliferation } \\
\hline PHA (cpm) & $>50,000$ & $>50,000$ & NA & NA & 45,441 & NA \\
\hline Anti-CD3 (cpm) & $>2,000$ & $>9,000$ & NA & NA & 14,337 & NA \\
\hline PMA + ionomicin (cpm) & $>60,000$ & $>60,000$ & NA & NA & 84,411 & NA \\
\hline \multicolumn{7}{|l|}{ NK cells } \\
\hline $\mathrm{CD}^{-}{ }^{-} \mathrm{CD}_{56}{ }^{+}\left(\mathrm{n}^{\circ} / \mu \mathrm{L}\right)$ & $80-600$ & $60-500$ & 16 & 4 & 8 & 1 \\
\hline \multicolumn{7}{|l|}{ NKT cells } \\
\hline $\mathrm{CD}^{+}{ }^{+} \mathrm{CD}_{56}+\left(\mathrm{n}^{\circ} / \mu \mathrm{L}\right)$ & $40-115$ & $35-85$ & 253 & 109 & 621 & 525 \\
\hline \multicolumn{7}{|l|}{ B cells } \\
\hline $\operatorname{CD} 19+(n \% / \mu L)$ & $200-700$ & $100-500$ & 48 & 34 & 21 & 18 \\
\hline $\mathrm{CD} 19+\mathrm{CD} 27^{+}(\%)$ & $7-19$ & $11.8-34.7$ & 36 & 71.3 & 24 & 62 \\
\hline CD19+IgD+CD27- (naive) (\%) & $75-89$ & $57.4-83.9$ & NA & 15.3 & 50.6 & 25 \\
\hline CD19+lgD+CD27+ (marginal zone) (\%) & $2.5-7$ & $4-11.8$ & NA & 18.4 & 16.5 & 31.9 \\
\hline $\mathrm{CD}^{19}{ }^{+} \operatorname{lgD}-\mathrm{CD} 27^{+}$(switching) (\%) & $4.5-13$ & $6.3-24.9$ & NA & 52.5 & 16.2 & 28.7 \\
\hline CD19+CD21 low (\%) & $3.3-9.5$ & $3.36-9.53$ & 14.3 & NA & 12 & 20.7 \\
\hline CD19+CD38+lgM+ (transitionals) (\%) & $1-9$ & $1-9$ & NA & NA & 7.8 & 0.5 \\
\hline CD19+CD38+lgM- (plasmablasts) (\%) & $0-2.5$ & $0-2.5$ & NA & NA & 2.5 & 6 \\
\hline Dendritic cells CD4+HLA-DR+CD123+ (\%) & $0.5-1$ & $0.5-1$ & 0.0 & 0.0 & 0.0 & 0.0 \\
\hline \multicolumn{7}{|l|}{ Serum immunoglobulins (mg/dL) } \\
\hline $\operatorname{lgG}(\mathrm{mg} / \mathrm{dL})$ & $600-1,230$ & $700-1,600$ & 1,040 & 2,070 & 643 & 2,580 \\
\hline $\lg \mathrm{A}(\mathrm{mg} / \mathrm{dL})$ & 30-200 & $70-400$ & 64 & 588 & 43 & 415 \\
\hline $\operatorname{lgM}(\mathrm{mg} / \mathrm{dL})$ & $50-200$ & $40-230$ & 73 & 207 & 98 & 218 \\
\hline \multicolumn{7}{|l|}{ Specific antibodies } \\
\hline IgG vs pneumococcus (mg/dL) & $>5.40$ & $>5.40$ & NA & NA & 10.4 & NA \\
\hline IgG2 vs pneumococcus (mg/dL) & $>2.14$ & $>2.14$ & NA & NA & 2.88 & NA \\
\hline IgG vs tetanus toxoid (IU/mL) & $>0.15$ & $>0.15$ & 0.40 & NA & 0.88 & NA \\
\hline Cytogenetics & & & $46, X X$ & $46, X Y$ & +8 & NA \\
\hline \multirow[t]{2}{*}{ Mutations } & & & R337X & M236lfs325X & K378X & T354M \\
\hline & & & de novo & de novo & de novo & $A D$ \\
\hline Clinical score & & & 0 & 0 & 2 & 3 \\
\hline
\end{tabular}

of DCs (Table 1). GATA2 Sanger sequencing identified a novel heterozygous mutation (c.708delC) that disrupts the correct transcription of the protein leading to a premature stop codon at the amino acid 325 (p.M236Ifs325X) (14). He is currently awaiting HSCT in stable condition, receiving G-CSF twice a week and daily valacyclovir prophylaxis to minimize herpes simplex virus infection or infection recurrence.

Patient 3 is an 8-year old girl with deafness requiring a hearing aid, since age 2 . She had recurrent pneumonia radiologically confirmed (at least three episodes required hospital admission). After azithromycin treatment was started respiratory infections decreased. Despite normal respiratory function tests at the age of 10, bilateral bronchiectasis and air trapping were present in a lung CT performed at that time. Physical examination revealed only mild lymphedema in her left leg. She started growth hormone therapy at the age of 9 , with subsequent response to hormone replacement. She presented with lymphopenia with low naive $\mathrm{CD} 4$ and $\mathrm{CD} 8 \mathrm{~T}$ cells, impaired proliferation to PHA, elevation of TCR $\gamma \delta$ T cells, and very low B and NK cells (Table 1). At this point, a combined immunodeficiency was suspected. ADA, RAG1, and RAG2 deficiency were excluded by Sanger sequencing. Finally, she was included in a targeted sequencing panel for PID. Gene variant analysis revealed an exonic nucleotide substitution in GATA2 (c.1132A $>$ T), not found in ExAC or 1,000 genomes database, that was predicted to cause a premature stop codon (p.K378X). Sanger sequencing confirmed these data. Despite normal bone marrow aspirate by optical microscopy and immunophenotyping, cytogenetic analysis revealed an abnormal karyotype 47, XX, +8 (57\%, 21 cells) and hyperdiploidy of more than 80 chromosomes $(24 \%$, 21 cells) (Table 1 ). She underwent HSCT from a fully matched sibling donor at the age of 13 . 
Patient 4 is a 37-year old woman referred from the Dermatology department for evaluation of genital and axillary warts refractory to treatment, extensive vulvar intraepithelial neoplasia grade III on labia majora, and persistent lymphedema of the vulva, combined with chronic anemia and thrombocytopenia due to bone marrow failure. The clinical history of the patient included bone marrow aplasia discovered at 14 years, after an episode of typhoid fever; chronic lung disease of unknown origin, that required surgical resection of the lower lobe of the left lung for bronchiectasis at 18 years; cytomegalovirus (CMV) pneumonia at age 23 requiring ICU admission for 15 days. She currently smokes and receives chronic treatment with inhaled bronchodilators. She has a substantial family history: one sister deceased at 35 years due to disseminated infection by Mycobacterium avium complex; her sister also had persistent warts and suffered a blood disorder similar to the patient. Their father died at 32 years of acute leukemia (DNA samples were not available). There were no other affected family members. GATA2 sequencing identified a nucleotide substitution (c.1061C>T) leading to p. T354M [described in Ref. (3)].

We clustered these four patients based on clinical complications to obtain the clinical score described in Ref. (9) in order to explore possible correlations between immunologic phenotype and clinical features (see Table 1; Table S3 in Supplementary Material). NK, B, and DC deficiency was observed in all four patients as well as impaired NK-cell cytotoxicity (Table 1; Figure S1 in Supplementary Material). Although B-cell numbers were globally decreased, the proportion of naïve, switched memory, and marginal zone B subpopulations were preserved.

\section{T-Cell Compartment Composition Exhibits Distinct Features in Accordance with Clinical Score}

Abnormalities in $\mathrm{T}$ cells have been described in patients with GATA2 deficiency (9). Here, we wanted to assess the impact of mutations in GATA2 on T-cell phenotypes and correlate these findings with the clinical presentations of our patients. Peripheral blood $\mathrm{CD}^{+} \mathrm{T}$-cell numbers and TCRV $\beta$ repertoire (data not shown) were studied by flow cytometry in GATA2-deficient patients and the data were comparable with age-matched controls (Table 1). However, the ratio of $\mathrm{CD}^{+} \mathrm{TCR} \alpha \beta^{+}$and $\mathrm{CD} 3^{+} \mathrm{TCR} \gamma \delta^{+}$ subpopulations was imbalanced in $\mathrm{P} 1-3$, and $\mathrm{CD} 3^{+} \mathrm{TCR} \gamma \delta^{+}$cells represented more than $15 \%$ of $\mathrm{CD}^{+} \mathrm{T}$ cells (controls $4.82 \pm 1.99$ ) (Figure 1A). In particular, $\mathrm{P} 3 \mathrm{had}$ a substantial increase in TCR $\gamma \delta^{+}$ that reached $56.4 \pm 9.1$ of total $\mathrm{CD}^{+} \mathrm{T}$ cells. $\mathrm{P} 4$ had proportions of both subpopulations similar to those of healthy donors.

P1 and P2, the patients with fewer clinical complications and a clinical score of 0 , presented normal subpopulations of CD4 and CD8 T cells compared with controls. The percentages of naïve $\mathrm{CD} 4\left(\mathrm{CD} 4{ }^{+} \mathrm{CCR} 7^{+} \mathrm{CD} 45 \mathrm{RA}{ }^{+}\right)$, memory $\mathrm{CD} 4$ $\left(\mathrm{CD} 4^{+} \mathrm{CCR} 7^{ \pm} \mathrm{CD} 45 \mathrm{RA}^{-}\right)$, naïve $\mathrm{CD} 8\left(\mathrm{CD}^{+} \mathrm{CCR} 7^{+} \mathrm{CD} 45 \mathrm{RA}^{+}\right)$, memory CD8 $\left(\mathrm{CD}^{+} \mathrm{CCR}^{ \pm} \mathrm{CD}^{\mathrm{C}} 4 \mathrm{RA}^{-}\right)$, and TEMRA CD8 $\left(\mathrm{CD}^{+} \mathrm{CCR}^{-} \mathrm{CD}^{-} 5 \mathrm{RA}^{+}\right) \mathrm{T}$ cells were within the range of age-matched related donors. Indeed, P1 had significantly higher levels of naïve CD4 (P1 $80.66 \pm 6.04 \%$, control children $59.96 \pm 11.72 \%$ ) and naïve CD8 T cells (P1 66.86 $\pm 6.00 \%$, control children $46.26 \pm 16.16 \%)$. In contrast, P3 and P4, clinically scored as 2 and 3, respectively, exhibited a profound decrease in naïve $\mathrm{T}$ CD4 (P3 22.56 \pm 13.39\%, control children $59.96 \pm 11.72 \%$; P4 $8.47 \pm 2.56 \%$, control adults $42.95 \pm 15.75 \%)$ and naïve T CD8 populations (P3 23.40 $\pm 10.51 \%$, control children $46.26 \pm 16.16 \%$; P4 $3.25 \pm 0.29 \%$, control adults $31.33 \pm 16.27 \%$ ) with a corresponding increase in memory CD4 T cells in both patients (P3 $69.66 \pm 8.50 \%$, control children $31.92 \pm 9.75 \%$; P $474.79 \pm 2.53 \%$, control adults $57.12 \pm 16.52 \%)$. The reduction in naïve CD8 $\mathrm{T}$ cells led to an elevation of memory CD8 T cells in P3 (P3 $59.40 \pm 15.51 \%$, control children $31.64 \pm 7.85 \%$ ) whereas in $\mathrm{P} 4$, the patient with higher clinical score, TEMRA CD8 T cells were increased compared with controls (P4 $54.43 \pm 10.98 \%$, control adults $14.83 \pm 8.39 \%$ ) (Figure 1B).

In order to better understand the T-cell phenotype in these patients, we studied several molecules that change during differentiation from naïve to effector cells. The reduction of the naïve T-cell compartment in patients 3 and 4 was accompanied by the expression of senescence markers on the surface of these cells. Naïve T CD4 cells of P3 and P4 showed significantly increased percentages of CD95 (P3 61.21 $\pm 14.44 \%$, control children $6.20 \pm 8.50 \%$; P4 $22.25 \pm 3.54 \%$, control adults $4.79 \pm 2.29 \%)$ with loss of CD27 (P3 91.26\%, control children $99.81 \pm 0.30 \%$; P4 $90.19 \pm 0.61 \%$, control adults $99.77 \pm 0.38 \%)$. Similar results were found in naïve CD8 T cells, where P3 and P4 showed increased levels of CD95 (P3 $18.44 \pm 7.60 \%$, control children $2.72 \pm 2.42 \% ; \mathrm{P} 410.04 \pm 0.50 \%$, control adults $3.01 \pm 2.78 \%)$ and decreased expression of CD27 (P4 $80.67 \pm 4.78 \%$, control adults $99.89 \pm 0.10 \%)$. Total CD $4^{+} \mathrm{T}$ cells expressed significantly higher levels of CD57 in P3 and P4 (P3 $11.00 \pm 2.82 \%$, control children $2.30 \pm 1.79 \%$; P4 $13.57 \pm 0.81 \%$, control adults $3.18 \pm 3.51 \%)$. CD57 expression was also elevated in CD8 T cells from P4 $(26.24 \pm 3.41 \%$, control adults $17.70 \pm 13.90 \%)$. In contrast, there was no differential expression of the CD27, CD28, CD127, CD57, and CD95 surface markers in P1 and P2 T cells (Figure 2). Intracytoplasmatic staining of cytotoxic granules in CD8 T-cell revealed reduced expression of granzyme B in $\mathrm{P} 1-3$, and normal values in $\mathrm{P} 4$. Although granzyme B expression was impaired in these patients, perforin and granzyme A staining was normal compared with healthy controls (Figure S1A in Supplementary Material). These results suggest that patients with a more severe clinical presentation of GATA2 deficiency have decreased naïve T-cell populations with a corresponding increase in terminally differentiated $\mathrm{T}$ cells.

\section{GATA2 Patients Displayed an Immature/ Activated NK-Cell Phenotype and Expansion of NKT Cells}

To determine the effect of GATA2 deficiency on NK-cell function and phenotype, we performed K562 target cell lysis assays and FACS phenotyping. NK-cell cytolytic function was abolished in all four patients (Figure S1B in Supplementary Material). Moreover, percentage and absolute counts of NK cells $\left(\mathrm{CD} 3^{-} \mathrm{CD} 56^{+}\right)$were markedly decreased (Figure 3A) with a seemingly total absence of the CD56 $6^{\text {bright }}$ subset as previously described (8). In addition, the NKT population $\left(\mathrm{CD}^{+} \mathrm{CD} 56^{+}\right)$was significantly increased in all patients (15). Patient 3 exhibited an extremely elevated 


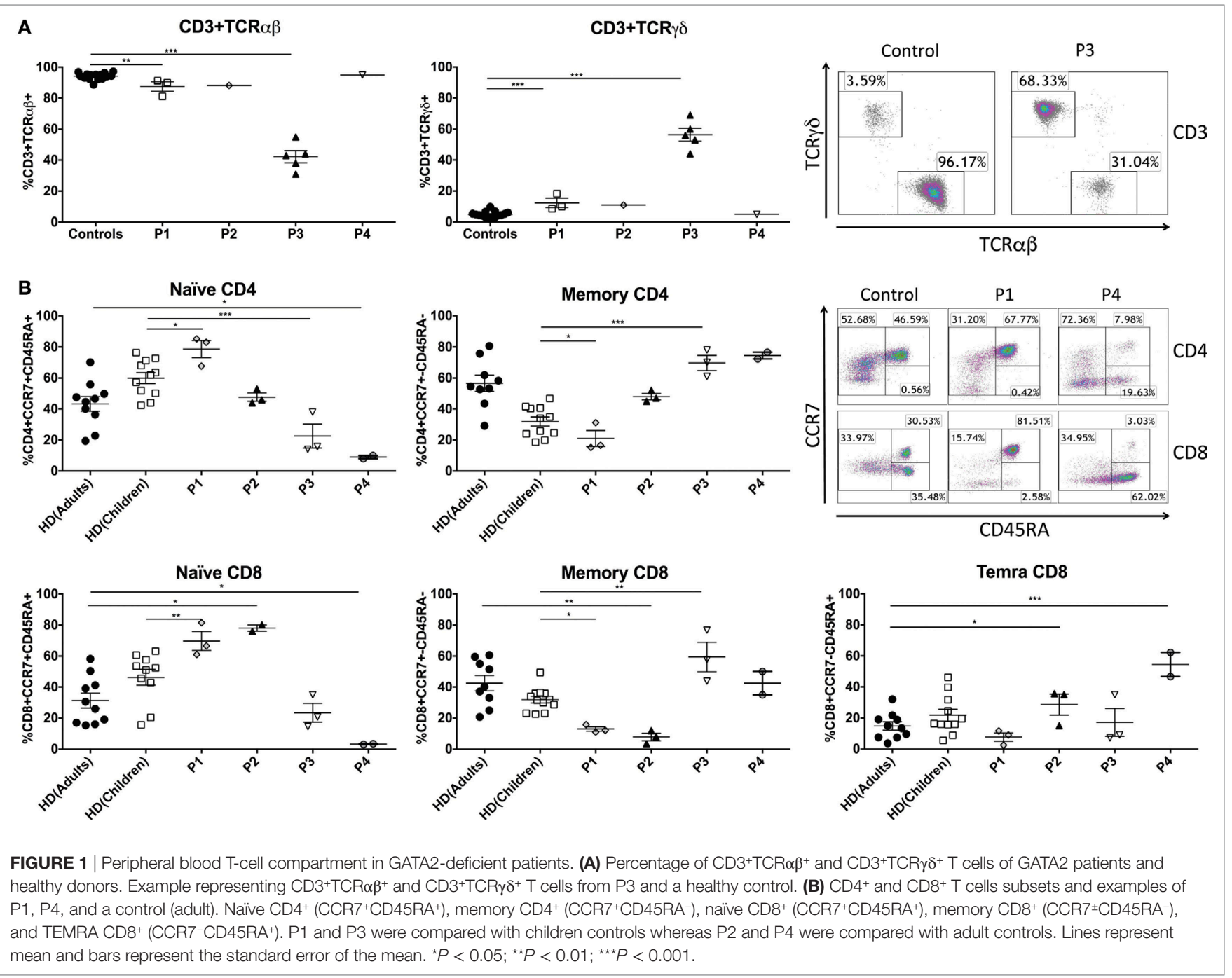

percentage of NKT cells, with an NKT frequency of $68.26 \pm 11.15 \%$ of total CD $45^{+}$lymphocytes (Figure 3B). To further study both NK- and NKT-cell phenotype in these patients, we analyzed a repertoire of 14 surface markers and 3 intracytoplasmic molecules involved in cytotoxicity (see Tables S4, S5, and Figure S2 in Supplementary Material). Our panels included markers that indicate various stages of differentiation/maturation (CD27, CD57, PERF1, GZMA, GZMB), activation/accessory receptors (CD25, CD69, CD2, CD8, CD16, DNAM1, NKG2D, NKp44, NKp46), and cell adhesion molecules (CD11a, CD11b, CD18).

We analyzed these molecules on CD56 ${ }^{\mathrm{dim}} \mathrm{NK}$ cells as they are considered the mature subset of NK cells and the CD56 $6^{\text {bright }}$ subset is severely decreased in GATA2 patients. We observed an impaired differentiation/maturation profile of these cells. P1-4 expressed significantly higher proportion of $\mathrm{CD} 27^{+}$cells than healthy controls (Figure 3C), a marker associated with immaturity of both CD56 bright and CD56 ${ }^{\text {dim }}$ human NK-cell subsets (16). CD57 expression was comparable with controls in P1, P3, and P4 and slightly reduced in P2. The proportion of perforin-expressing cells was reduced in P2, P3, and P4. We did not observe differential expression of granzyme A in P1, P2, and P3, in contrast, all patients had diminished levels of granzyme $\mathrm{B}$ in NK cells (Figure S1C in Supplementary Material). The proportion of CD27-expressing NKT cells was elevated in P1, but there were no other findings of interest from our studies on NKT-cell differentiation/maturation markers (Table S5 in Supplementary Material). Additionally, while the percentage of positive cells was altered, there was no differential expression of these markers on a per-cell basis when MFI was measured on NK or NKT cells (data not shown).

Activation of NK cells was measured by expression of CD25 and CD69. P2-4 showed increased proportions of CD25 (Figure 3D) and CD69 expressing cells (Figure 3E), whereas P1 only had a slight increase in CD25 expression. The proportion of NK cells expressing other accessory molecules, including DNAM1, was decreased in all patients (Figure 3F). The frequency of CD16 expressing NK cells was inversely proportional to the clinical score in all patients and $\mathrm{P} 4$, in particular exhibited a marked decrease in CD16 expression by CD56 $6^{\mathrm{dim}} \mathrm{NK}$ cells, while P1 presented normal levels and P2, 3 only had slight reductions 


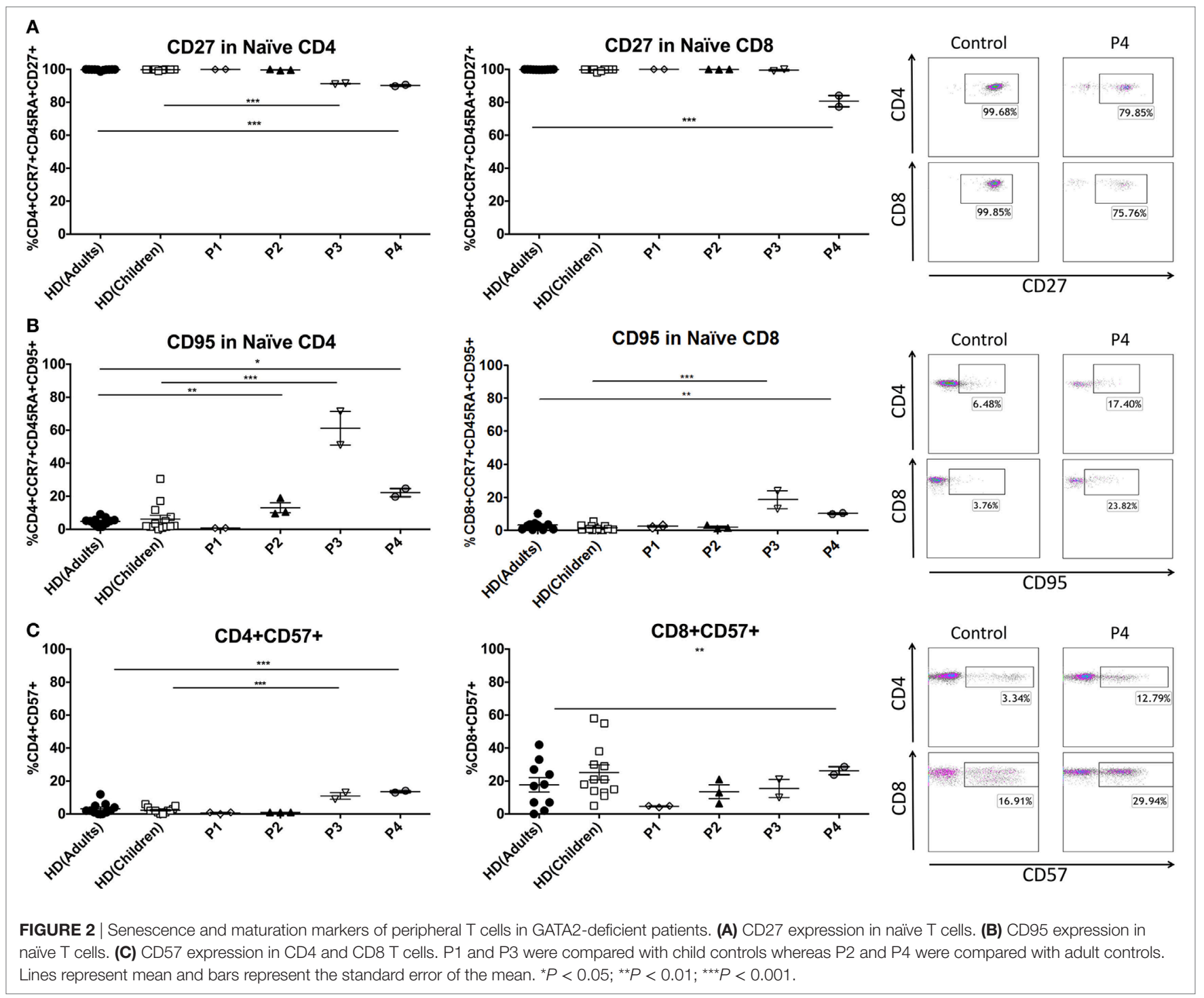

(Figure 3G; Figure S1D in Supplementary Material). Higher percentages of $\mathrm{CD} 8 \alpha^{+} \mathrm{NK}$ cells (Figure $3 \mathrm{H}$ ) were observed in GATA2 patient NK cells in comparison with controls while other markers shared with T cells like CD2 were expressed normally. The expression of a range of activating receptors (NKG2D, NKp44, NKp46) was similar to healthy donors (see Table S4 in Supplementary Material). NKT cells expressed higher levels of CD69 in P2-4. CD2 expression was increased in patients P1-3 (see Table S5 in Supplementary Material). Finally, there was no differential expression of cell adhesion markers such as CD18, CD11a, and CD11b compared with healthy donors in NK or NKT cells (Tables S4 and S5 in Supplementary Material).

\section{DISCUSSION}

The GATA2 transcription factor plays a critical role in hematopoietic stem cell (HSC) maintenance and survival (17). Its absence in $\mathrm{Gata}^{-/-}$mice causes embryonic lethality due to a deficient maturation of HSC to different hematopoietic lineages (18). In humans, haploinsufficiency of GATA2 caused by heterozygous spontaneous or autosomal dominant mutations causes a wide spectrum of clinical implications ranging from lymphedema, predisposition to mycobacterial, and viral infections to bone marrow failure with MDS/AML. Numerous mutations in GATA2 gene have been described as the cause of this heterogeneous disease (1-4, 6 , $12,19)$. Here, we present a detailed analysis of four GATA2deficient patients, two with previously reported mutations (P1 and P4) and another two where we describe two novel mutations in GATA2, p.M236Ifs325X and p.K378X (found in patients 2 and 3, respectively). Importantly, our analysis has revealed a correlation between the altered lymphocyte development in these patients and the different clinical pictures and clinical scores.

In GATA2 syndrome, monocytes, B, NK, and DC populations are profoundly diminished or undetectable (6) and DC were essentially absent in all four of these patients, underscoring the importance of GATA2 as an essential regulator of DC 


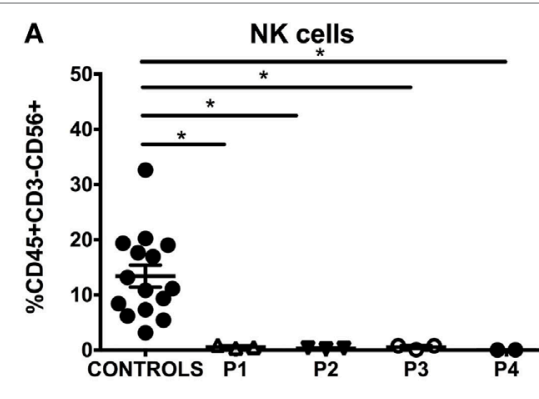

C
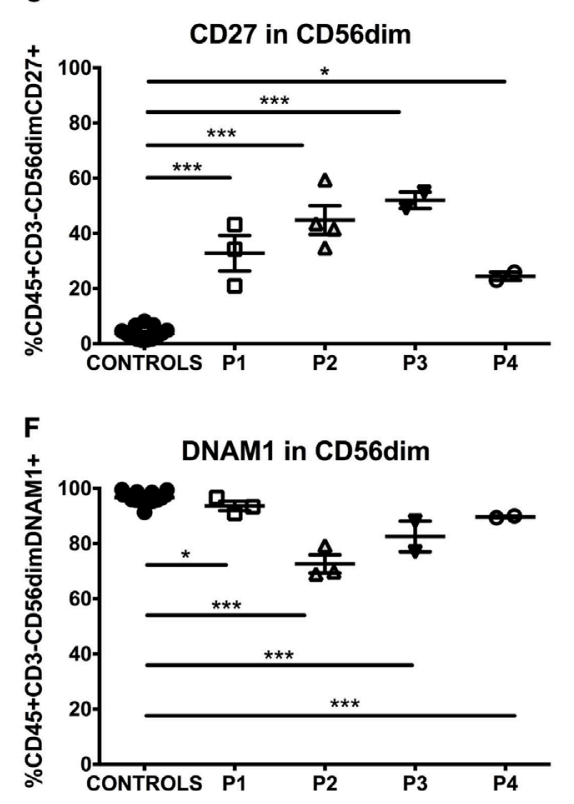

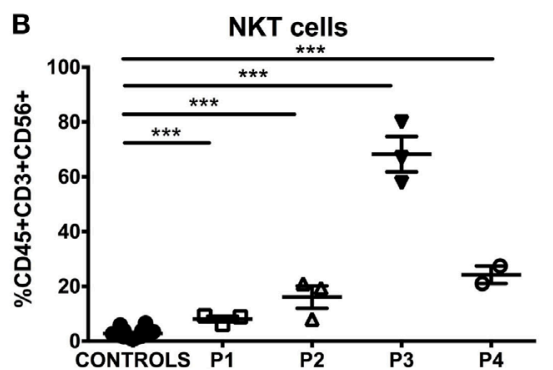

D
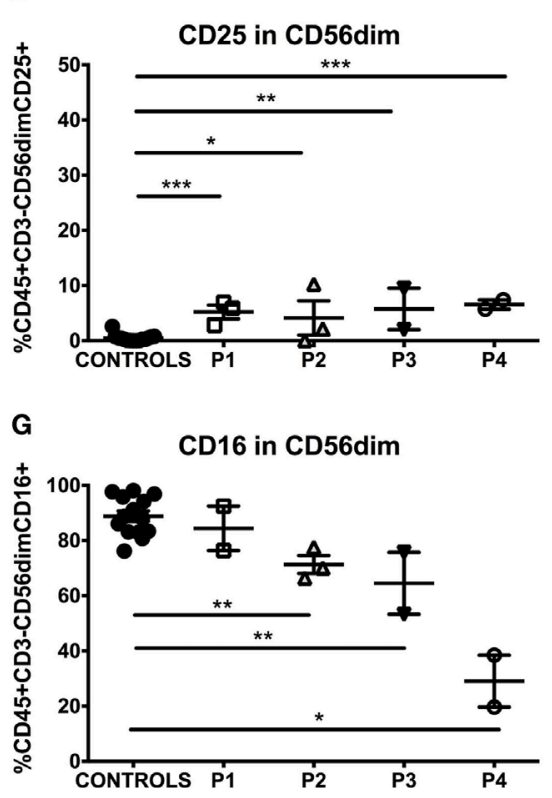

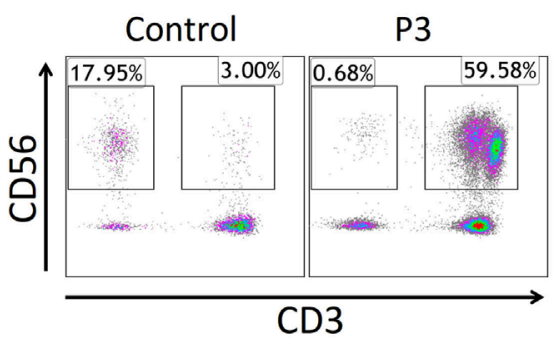

E
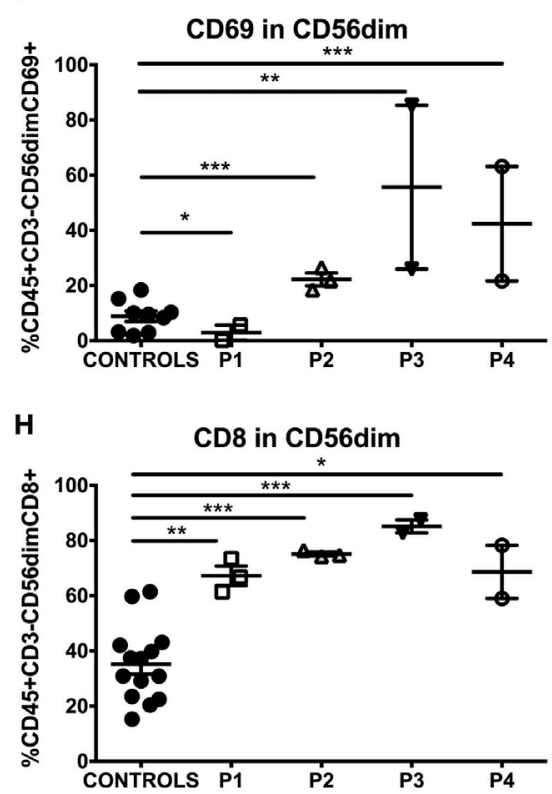

FIGURE 3 | NK- and NKT-cell phenotype in GATA2-deficient patients. (A) Percentage of NK cells (CD3-CD56 ${ }^{+}$) of GATA2 patients and controls. (B) Percentage of NKT cells (CD3+CD56+) of GATA2 patients and healthy donors. (C) CD27 expression in CD56 dim NK cells. (D) CD25 expression in CD56 dim NK cells. (E) CD69 expression in CD56 dim NK cells. (F) DNAM1 expression in CD56 dim NK cells. (G) CD16 expression in CD56 dim NK cells. (H) CD8 expression in CD56 dim NK cells. Lines represent mean and bars represent the standard error of the mean. ${ }^{\star} P<0.05 ;{ }^{\star \star} P<0.01 ;{ }^{\star \star \star} P<0.001$.

differentiation (20). Although B-cell numbers were decreased, switched memory cells were present and no apparent functional defect was detected, with all patients having correct specific responses to immunization. P2 and P3 had mild decrease of naïve CD27 B cells. Monocytes were absent in P1 and P2, suggesting that they are the two patients that best match the classic description of DCML deficiency, while P3 and P4 had close to normal monocyte numbers. In this study, three patients out of four had increased frequencies of TCR $\gamma \delta \mathrm{T}$ cells and all had expanded NKT-cell populations. An elevation of TCR $\gamma \delta$ $T$ cells has been observed in some combined immunodeficiencies such as recombination activating gene 1,2 deficiency (21, $22), \operatorname{CD} 3 \gamma$, and $\operatorname{CD} 3 \delta(23,24)$, as a consequence of $\mathrm{CMV}$ infection or delayed-onset combined immune deficiency with granuloma and/or autoimmunity (25-27). While the source of the defect in innate-like T cells in GATA2 deficiency is unclear, it is possible that the markedly reduced numbers of antigen presenting cells (DC, monocytes, and B cells) could produce a dysregulated increase of invariant T cells such as TCR $\gamma \delta$ and NKT cells (9).
Abnormalities in the T-cell compartment have been described in GATA2 patients previously. Dickinson and collaborators described a cohort of patients where some showed increased frequency of terminal effector $\mathrm{CD} 8^{+} \mathrm{T}$ cells $(28,29)$. In our work, naïve $T$ cells were decreased in number and, importantly, an abnormal phenotype of those $\mathrm{T}$ cells was noted in those patients with more clinical complications (P3, P4), with increased expression of CD57 and CD95 in CD4 naïve cells. In contrast, P2 had normal percentages of cells expressing these markers compared with age-matched donors and P1 even had elevated naïve CCR ${ }^{+} \mathrm{CD} 45 \mathrm{RA}^{+} \mathrm{CD} 8^{+} \mathrm{T}$ cells. The senescent phenotype in $\mathrm{P} 3$ and $\mathrm{P} 4$ could be associated with replicative senescence resulting from continuous antigen stimulation as seen in repeated viral infections in other primary immunodeficiencies $(13,30)$.

Other NK-cell immunophenotyping studies in GATA2deficient patients have shown a largely unaffected repertoire of surface markers with some alterations in molecules like CD27 and CD117 (8). Here, NK cells of GATA2 patients showed an immature/activated phenotype, with increased proportions of CD27, CD25, and CD69 and decreased perforin and DNAM1. It is intriguing that 
NK cells from GATA2-deficient patients share features of both mature (CD56 ${ }^{\mathrm{dim}}$, Perforin, Granzyme...) and immature cells (upregulation of CD27, CD25, and CD69 and downregulation of CD16 and DNAM1). It is tempting to speculate that these NK cells could be in an intermediate maturation stage between stage 4 and stage 5 (31) in which GATA2 plays a fundamental role (32). The lack of DCs secreting IL12 and IL15 may also be an important factor contributing to the altered NK-cell maturation and activity $(33,34)$. With the exception of CD16 expression, the correlation between a senescent phenotype and higher clinical score that we observed for the T-cell compartment of GATA2 patients was not observed in our analysis of NK-cell phenotype.

In summary, this study expands the knowledge of GATA2 deficiency via detailed description of the different disturbances in the T- and NK-cell compartments of GATA2-deficient patients. The T-cell alterations could be secondary changes due to recurrent infections that lead to continuous antigen stimulation, but whatever the basis of these changes it is important to note that they are associated with a higher clinical score. In contrast, GATA2 deficiency produces an intrinsic NK-cell defect that seems to be independent from clinical score. With the caveat that we have studied a relatively small cohort, and it would be interesting to analyze more GATA2 patients, our data strongly suggest that the, analysis of lymphocyte subsets can provide indispensable knowledge in the symptomatic and presymptomatic stage of patients with GATA2 deficiency that could help when HSCT is being considered soon after the diagnosis.

\section{ETHICS STATEMENT}

All subjects gave written informed consent in accordance with the Declaration of Helsinki. The protocol was approved by the

\section{REFERENCES}

1. Ostergaard P, Simpson MA, Connell FC, Steward CG, Brice G, Woollard WJ, et al. Mutations in GATA2 cause primary lymphedema associated with a predisposition to acute myeloid leukemia (Emberger syndrome). Nat Genet (2011) 43(10):929-31. doi:10.1038/ng.923

2. Kazenwadel J, Secker GA, Liu YJ, Rosenfeld JA, Wildin RS, Cuellar-Rodriguez J, et al. Loss-of-function germline GATA2 mutations in patients with MDS/AML or MonoMAC syndrome and primary lymphedema reveal a key role for GATA2 in the lymphatic vasculature. Blood (2012) 119(5):1283-91. doi:10.1182/blood-2011-08-374363

3. Hahn CN, Chong CE, Carmichael CL, Wilkins EJ, Brautigan PJ, Li XC, et al. Heritable GATA2 mutations associated with familial myelodysplastic syndrome and acute myeloid leukemia. Nat Genet (2011) 43(10):1012-7. doi:10.1038/ng.913

4. Hsu AP, Sampaio EP, Khan J, Calvo KR, Lemieux JE, Patel SY, et al. Mutations in GATA2 are associated with the autosomal dominant and sporadic monocytopenia and mycobacterial infection (MonoMAC) syndrome. Blood (2011) 118(10):2653-5. doi:10.1182/blood-2011-05-356352

5. Pasquet M, Bellanne-Chantelot C, Tavitian S, Prade N, Beaupain B, Larochelle $\mathrm{O}$, et al. High frequency of GATA2 mutations in patients with mild chronic neutropenia evolving to MonoMac syndrome, myelodysplasia, and acute myeloid leukemia. Blood (2013) 121(5):822-9. doi:10.1182/ blood-2012-08-447367

6. Dickinson RE, Griffin H, Bigley V, Reynard LN, Hussain R, Haniffa M, et al. Exome sequencing identifies GATA-2 mutation as the cause of dendritic cell, monocyte, B and NK lymphoid deficiency. Blood (2011) 118(10):2656-8. doi:10.1182/blood-2011-06-360313
"Comité de Ética de la Investigación, Hospital 12 de Octubre." Patients or their parents/guardians gave written consent to publish the case reports.

\section{AUTHOR CONTRIBUTIONS}

RR-G performed the laboratory work for this study, and drafted the manuscript. CR-V, FM, CM-R, JR-C, and LG-G were responsible for the clinical management of the patients. FG-B, MC-P, LD-A, and EP-A collaborated in laboratory work. LA designed the study and drafted the manuscript. LG-G and LA contributed equally to this work.

\section{ACKNOWLEDGMENTS}

We thank Alejandra Leyva and Joaquín Martínez for monoclonal antibody sharing, Maite Fernandez, Miguela Menchén and María José Díaz-Madroñero for their technical assistance and Emily Mace and Hugh Reyburn for critical review of this article.

\section{FUNDING}

This work was supported by grants from Fondo de Investigación Sanitaria (FIS-PI11/1591 and FIS-PI16/2053) to LA and LG-G. The project has been co-financed with FEDER funds and PI2016/0044 to LG-G.

\section{SUPPLEMENTARY MATERIAL}

The Supplementary Material for this article can be found online at http://journal.frontiersin.org/article/10.3389/fimmu.2017.00802/ full\#supplementary-material.

7. Novakova M, Zaliova M, Sukova M, Wlodarski M, Janda A, Fronkova E, et al. Loss of B cells and their precursors is the most constant feature of GATA-2 deficiency in childhood myelodysplastic syndrome. Haematologica (2016) 101(6):707-16. doi:10.3324/haematol.2015.137711

8. Mace EM, Hsu AP, Monaco-Shawver L, Makedonas G, Rosen JB, Dropulic L, et al. Mutations in GATA2 cause human NK cell deficiency with specific loss of the CD56(bright) subset. Blood (2013) 121(14):2669-77. doi:10.1182/blood-2012-09-453969

9. Dickinson RE, Milne P, Jardine L, Zandi S, Swierczek SI, McGovern N, et al. The evolution of cellular deficiency in GATA2 mutation. Blood (2014) 123(6):863-74. doi:10.1182/blood-2013-07-517151

10. Spinner MA, Sanchez LA, Hsu AP, Shaw PA, Zerbe CS, Calvo KR, et al. GATA2 deficiency: a protean disorder of hematopoiesis, lymphatics, and immunity. Blood (2014) 123(6):809-21. doi:10.1182/blood-2013-07515528

11. Johnson KD, Hsu AP, Ryu MJ, Wang J, Gao X, Boyer ME, et al. Cis-element mutated in GATA2-dependent immunodeficiency governs hematopoiesis and vascular integrity. J Clin Invest (2012) 122(10):3692-704. doi:10.1172/ JCI61623

12. Hsu AP, Johnson KD, Falcone EL, Sanalkumar R, Sanchez L, Hickstein DD, et al. GATA2 haploinsufficiency caused by mutations in a conserved intronic element leads to MonoMAC syndrome. Blood (2013) 121(19):S1-7. doi:10.1182/blood-2012-08-452763

13. Ruiz-Garcia R, Lermo-Rojo S, Martinez-Lostao L, Mancebo E, Mora-Diaz S, Paz-Artal E, et al. A case of partial dedicator of cytokinesis 8 deficiency with altered effector phenotype and impaired CD8(+) and natural killer cell cytotoxicity. J Allergy Clin Immunol (2014) 134(1):218-21. doi:10.1016/j.jaci.2014.01.023 
14. Delgado-Marquez AM, Zarco C, Ruiz R, Simarro A, Vanaclocha F. Severe disseminated primary herpes simplex infection as skin manifestation of GATA2 deficiency. J Eur Acad Dermatol Venereol (2016) 30(7):1248-50. doi:10.1111/ jdv.13183

15. Maciejewski-Duval A, Meuris F, Bignon A, Aknin ML, Balabanian K, Faivre L, et al. Altered chemotactic response to CXCL12 in patients carrying GATA2 mutations. J Leukoc Biol (2016) 99(6):1065-76. doi:10.1189/ jlb.5MA0815-388R

16. Vossen MT, Matmati M, Hertoghs KM, Baars PA, Gent MR, Leclercq G, et al. CD27 defines phenotypically and functionally different human NK cell subsets. J Immunol (2008) 180(6):3739-45. doi:10.4049/jimmunol.180.6.3739

17. Tsai FY, Orkin SH. Transcription factor GATA-2 is required for proliferation/ survival of early hematopoietic cells and mast cell formation, but not for erythroid and myeloid terminal differentiation. Blood (1997) 89(10):3636-43.

18. Tsai FY, Keller G, Kuo FC, Weiss M, Chen J, Rosenblatt M, et al. An early haematopoietic defect in mice lacking the transcription factor GATA-2. Nature (1994) 371(6494):221-6. doi:10.1038/371221a0

19. Wlodarski MW, Hirabayashi S, Pastor V, Stary J, Hasle H, Masetti R, et al. Prevalence, clinical characteristics, and prognosis of GATA2-related myelodysplastic syndromes in children and adolescents. Blood (2016) 127(11):1387-97; quiz 518. doi:10.1182/blood-2015-09-669937

20. Onodera K, Fujiwara T, Onishi Y, Itoh-Nakadai A, Okitsu Y, Fukuhara N, et al. GATA2 regulates dendritic cell differentiation. Blood (2016) 128(4):508-18. doi:10.1182/blood-2016-02-698118

21. de Villartay JP, Lim A, Al-Mousa H, Dupont S, Dechanet-Merville J, CoumauGatbois E, et al. A novel immunodeficiency associated with hypomorphic RAG1 mutations and CMV infection. J Clin Invest (2005) 115(11):3291-9. doi:10.1172/JCI25178

22. Villa A, Sobacchi C, Notarangelo LD, Bozzi F, Abinun M, Abrahamsen TG, et al. V(D)J recombination defects in lymphocytes due to RAG mutations: severe immunodeficiency with a spectrum of clinical presentations. Blood (2001) 97(1):81-8. doi:10.1182/blood.V97.1.81

23. Munoz-Ruiz M, Perez-Flores V, Garcillan B, Guardo AC, Mazariegos MS, Takada H, et al. Human CD3gamma, but not CD3delta, haploinsufficiency differentially impairs gammadelta versus alphabeta surface TCR expression. BMC Immunol (2013) 14:3. doi:10.1186/1471-2172-14-3

24. Gil J, Busto EM, Garcillan B, Chean C, Garcia-Rodriguez MC, Diaz-Alderete A, et al. A leaky mutation in CD3D differentially affects alphabeta and gammadelta $\mathrm{T}$ cells and leads to a Talphabeta-Tgammadelta+B+NK+ human SCID. J Clin Invest (2011) 121(10):3872-6. doi:10.1172/JCI44254

25. Schuetz C, Huck K, Gudowius S, Megahed M, Feyen O, Hubner B, et al. An immunodeficiency disease with RAG mutations and granulomas. $N$ Engl J Med (2008) 358(19):2030-8. doi:10.1056/NEJMoa073966
26. Henderson LA, Frugoni F, Hopkins G, de Boer H, Pai SY, Lee YN, et al. Expanding the spectrum of recombination-activating gene 1 deficiency: a family with early-onset autoimmunity. J Allergy Clin Immunol (2013) 132(4):969-71.e1-2. doi:10.1016/j.jaci.2013.06.032

27. Lee YN, Frugoni F, Dobbs K, Walter JE, Giliani S, Gennery AR, et al. A systematic analysis of recombination activity and genotype-phenotype correlation in human recombination-activating gene 1 deficiency. J Allergy Clin Immunol (2014) 133(4):1099-108. doi:10.1016/j.jaci.2013.10.007

28. Brenchley JM, Karandikar NJ, Betts MR, Ambrozak DR, Hill BJ, Crotty LE, et al. Expression of CD57 defines replicative senescence and antigen-induced apoptotic death of CD8 ${ }^{+}$T cells. Blood (2003) 101(7):2711-20. doi:10.1182/ blood-2002-07-2103

29. Appay V, van Lier RA, Sallusto F, Roederer M. Phenotype and function of human T lymphocyte subsets: consensus and issues. Cytometry A (2008) 73(11):975-83. doi:10.1002/cyto.a.20643

30. Randall KL, Chan SS, Ma CS, Fung I, Mei Y, Yabas M, et al. DOCK8 deficiency impairs CD8 T cell survival and function in humans and mice. J Exp Med (2011) 208(11):2305-20. doi:10.1084/jem.20110345

31. Freud AG, Caligiuri MA. Human natural killer cell development. Immunol $\operatorname{Rev}(2006)$ 214:56-72. doi:10.1111/j.1600-065X.2006.00451.X

32. Mace EM, Gunesch JT, Dixon A, Orange JS. Human NK cell development requires CD56-mediated motility and formation of the developmental synapse. Nat Commun (2016) 7:12171. doi:10.1038/ncomms12171

33. Walzer T, Dalod M, Robbins SH, Zitvogel L, Vivier E. Natural-killer cells and dendritic cells: "l'union fait la force". Blood (2005) 106(7):2252-8. doi:10.1182/ blood-2005-03-1154

34. Biron CA, Nguyen KB, Pien GC, Cousens LP, Salazar-Mather TP. Natural killer cells in antiviral defense: function and regulation by innate cytokines. Annu Rev Immunol (1999) 17:189-220. doi:10.1146/annurev.immunol. 17.1.189

Conflict of Interest Statement: The authors declare that the research was conducted in the absence of any commercial or financial relationships that could be construed as a potential conflict of interest.

Copyright (C) 2017 Ruiz-García, Rodríguez-Vigil, Marco, Gallego-Bustos, CastroPanete, Diez-Alonso, Muñoz-Ruiz, Ruiz-Contreras, Paz-Artal, González-Granado and Allende. This is an open-access article distributed under the terms of the Creative Commons Attribution License (CC BY). The use, distribution or reproduction in other forums is permitted, provided the original author(s) or licensor are credited and that the original publication in this journal is cited, in accordance with accepted academic practice. No use, distribution or reproduction is permitted which does not comply with these terms. 